ano 15 - n. 61 I julho/setembro - 2015

Belo Horizonte I p. 1-270 I ISSN 1516-3210

A\&C - R. de Dir. Administrativo \& Constitucional

Revista de Direito ADMINISTRATIVO \& CONSTITUCIONAL

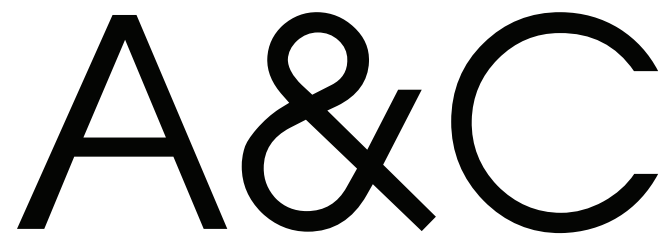




\section{A\&C - REVISTA DE DIREITO ADMINISTRATIVO \& CONSTITUCIONAL}

IPDA

Instituto Paranaense

de Direito Administrativo
ROMEU DEUPE

BACELLAR

๑) 2015 Editora Fórum Ltda.

Todos os direitos reservados. É proibida a reprodução total ou parcial, de qualquer forma ou por qualquer meio eletrônico ou mecânico, inclusive através de processos xerográficos, de fotocópias ou de gravação, sem permissão por escrito do possuidor dos direitos de cópias (Lei no 9.610, de 19.02.1998).

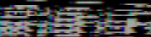

Luís Cláudio Rodrigues Ferreira

Presidente e Editor

Av. Afonso Pena, 2770 - 16ํandar - Funcionários - CEP 30130-007 - Belo Horizonte/MG - Brasil - Tel.: 08007043737 www.editoraforum.com.br / E-mail: editoraforum@editoraforum.com.br

Impressa no Brasil / Printed in Brazil / Distribuída em todo o Território Nacional

Os conceitos e opiniões expressas nos trabalhos assinados são de responsabilidade exclusiva de seus autores.

A246 A\&C : Revista de Direito Administrativo \&
Constitucional. - ano 3, n. 11, jan./mar.
2003)- . - Belo Horizonte: Fórum, 2003-
Trimestral
ISSN: 1516-3210
Ano 1, n. 1, 1999 até ano 2, n. 10, 2002 publicada
pela Editora Juruá em Curitiba
$\begin{aligned} & \text { 1. Direito administrativo. 2. Direito constitucional. } \\ & \text { I. Fórum. } \\ & \text { CDD: } 342 \\ & \text { CDU: } 342.9\end{aligned}$

Supenvisão editorial: Leonardo Eustáquio Siqueira Araújo

Capa: Igor Jamur

Projeto gráfico: Walter Santos

\section{Periódico classificado no Estrato A1 do Sistema Qualis da CAPES - Área: Direito.}

Revista do Programa de Pós-graduação do Instituto de Direito Romeu Felipe Bacellar (Instituição de Pesquisa e Pós-Graduação), em convênio com o Instituto Paranaense de Direito Administrativo (entidade associativa de âmbito regional filiada ao Instituto Brasileiro de Direito Administrativo). A linha editorial da $A \& C$ - Revista de Direito Administrativo \& Constitucional segue as diretrizes do Programa de Pós-Graduação do Instituto de Direito Romeu Felipe Bacellar em convênio com o Instituto Paranaense de Direito Administrativo. Procura divulgar as pesquisas desenvolvidas na área de Direito Constitucional e de Direito Administrativo, com foco na questão da efetividade dos seus institutos não só no Brasil como no direito comparado, com ênfase na questão da interação e efetividade dos seus institutos, notadamente América Latina e países europeus de cultura latina.

A publicação é decidida com base em pareceres, respeitando-se o anonimato tanto do autor quanto dos pareceristas (sistema double-blind peer review).

Desde o primeiro número da Revista, $75 \%$ dos artigos publicados (por volume anual) são de autores vinculados a pelo menos cinco instituições distintas do Instituto de Direito Romeu Felipe Bacellar.

A partir do volume referente ao ano de 2008 , pelo menos $15 \%$ dos artigos publicados são de autores filiados a instituições estrangeiras.

Esta publicação está catalogada em:

- Ulrich's Periodicals Directory

- RVBI (Rede Virtual de Bibliotecas - Congresso Nacional)

- Library of Congress (Biblioteca do Congresso dos EUA)

A\&C - Revista de Direito Administrativo \& Constitucional realiza permuta com as seguintes publicações: - Revista da Faculdade de Direito, Universidade de São Paulo (USP), ISSN 0303-9838

- Rivista Diritto Pubblico Comparato ed Europeo, ISBN/EAN 978-88-348-9934-2 
Diretor-Geral

Romeu Felipe Bacellar Filho

Diretor Editorial

Paulo Roberto Ferreira Motta

Editores Acadêmicos Responsáveis

Daniel Wunder Hachem

Ana Cláudia Finger

Assessor Editorial

Felipe Klein Gussoli

\section{Conselho Editorial}

Adilson Abreu Dallari (PUC-SP) Juan Pablo Cajarville Peluffo (Universidad de La República - Uruguai) ardo Schier (Instituto Bacellar) Justo J. Reyna (Universidad Nacional del Litoral - Argentina)

Alice Gonzalez Borges (UFBA) Juarez Freitas (UFRGS)

Carlos Ari Sundfeld (FGV-SP) Luís Enrique Chase Plate (Universidad Nacional de Asunción - Paraguai)

Carlos Ayres Britto (UFSE) Marçal Justen Filho (UFPR)

Adriana da Costa Ricardo Schier (Instituto Bacellar)
Alice Gonzalez Borges (UFBA)

Marcelo Figueiredo (PUC-SP)

Márcio Cammarosano (PUC-SP)

Carlos Delpiazzo (Universidad de La República - Uruguai) Cármen Lúcia Antunes Rocha (PUC Minas) Célio Heitor Guimarães (Instituto Bacellar) Celso Antônio Bandeira de Mello (PUC-SP) Clèmerson Merlin Clève (UFPR) Clovis Beznos (PUC-SP) Edgar Chiuratto Guimarães (Instituto Bacellar) Maria Cristina Cesar de Oliveira (UFPA)

Nelson Figueiredo (UFG)

Odilon Borges Junior (UFES)

Pascual Caiella (Universidad de La Plata - Argentina)

Emerson Gabardo (UFPR)

Paulo Eduardo Garrido Modesto (UFBA)

Paulo Henrique Blasi (UFSC)

Enrique Silva Cimma (Universidad de Chile - Chile) Eros Roberto Grau (USP)

Irmgard Elena Lepenies (Universidad Nacional del Litoral - Argentina) de La Coruña - Espanha)

Pedro Paulo de Almeida Dutra (UFMG)

Regina Maria Macedo Nery Ferrari (UFPR)

Rogério Gesta Leal (UNISC)

Rolando Pantoja Bauzá (Universidad Nacional de Chile - Chile)

Sergio Ferraz (PUC-Rio)

Valmir Pontes Filho (UFCE)

José Eduardo Martins Cardoso (PUC-SP)

José Luís Said (Universidad de Buenos Aires - Argentina) José Mario Serrate Paz (Universidad de Santa Cruz - Bolívia)

Yara Stroppa (PUC-SP)

\section{Homenagem Especial}

Guillermo Andrés Muñoz (in memoriam) Jorge Luís Salomoni (in memoriam) Julio Rodolfo Comadira (in memoriam) Lúcia Valle Figueiredo (in memoriam)

Manoel de Oliveira Franco Sobrinho (in memoriam) Paulo Neves de Carvalho (in memoriam) 


\title{
O primeiro passo na Grande Marcha: legislação e prática do Governo Aberto à Informação (GAl) na China*
}

\author{
Jiang Ming'an \\ Professor na Faculdade de Direito da Universidade de Pequim (China) e Diretor do Centro \\ de Estudos de Direito Constitucional e Administrativo da Universidade de Pequim. Seu \\ principal campo de pesquisa diz respeito ao Direito Administrativo e ao Direito Administrativo \\ contencioso na China. E-mail: <jma@pku.edu.cn>.
}

\section{Tan Daoming}

Doutor pela Faculdade de Direito da Universidade de Pequim e pesquisador assistente do Instituto de Estudos Latino-Americanos (IELA), Academia Chinesa de Ciências Sociais (ACCS), com ênfase no constitucionalismo e no Estado de Direito dos países da América Latina. E-mail: <tandm@cass.org.cn>.

\begin{abstract}
Resumo: $O$ artigo em referência tem como tema central os aspectos legais e práticos do denominado "Governo Aberto à Informação (GAl)" na China. O texto demonstra as dificuldades de implementação e desenvolvimento de uma questão que se encontra no núcleo das preocupações do governo chinês: a tentativa de abandonar seu modelo de economia planificada, construindo governos mais transparentes, de modo a concretizar políticas de livre mercado. Nesse contexto, os autores se voltam ao desenvolvimento de conceitos basilares, como os de publicidade e informação, respeitadas as peculiaridades da realidade chinesa. Enfocam, ainda, as exceções que tais direitos comportam e suas limitações legais, identificando a falta de bases constitucionais claras como sua principal problemática. De todo modo, o artigo apresenta uma perspectiva atual e revisitada do direito à informação na China, pautada em casos práticos e em projeções futuras sobre os caminhos do governo aberto chinês.
\end{abstract}

\footnotetext{
* Tradução do original em inglês para o português, realizada por Ricardo Perlingeiro (Professor da Faculdade de Direito da Universidade Federal Fluminense e Desembargador Federal do Tribunal Regional Federal da

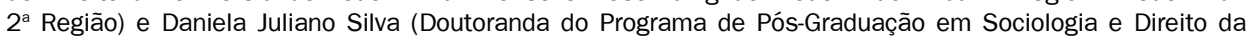
Universidade Federal Fluminense [PPGSD/UFF] e advogada). Os autores agradecem a Bu Chao (doutorando da Faculdade de Direito da Universidade de Pequim) por sua generosa ajuda na preparação deste artigo.

Abreviações:

CAPL - Comitê de Assuntos Políticos e Legislativos

CEAPP - Centro de Estudos e Apoio para a Participação Pública (Universidade de Pequim, China)

CNP - Congresso Nacional do Povo (China)

CPCNP - Comitê Permanente do Congresso Nacional do Povo

GAI - Governo Aberto à Informação

LCA - Lei do Contencioso Administrativo (China)

LSP - Lei dos Servidores Públicos da República Popular da China (China)

LTSE - Lei da Tutela do Segredo de Estado (China)

OMC - Organização Mundial do Comércio

ONGs - Organizações não governamentais

PCC - Partido Comunista Chinês
} 
Palavras-chave: Acesso à informação. China. Governo Aberto à Informação.

Sumário: 1 Introdução - 2 Princípios gerais - 3 Principais conteúdos - 4 Várias deficiências - 5 Alguns aspectos na prática - $\mathbf{6} 0$ futuro do GAI na China - Referências

\section{Introdução}

Na China, durante a primavera e o outono (China antiga há 2.000 anos), Zi Chan e Shu Xiang, dois políticos do Estado de Zheng, debateram acerca do seguinte tópico: se o povo deveria ter conhecimento da lei. ${ }^{1} \mathrm{Zi}$ Chan liberava a lei penal ao público, no que era fortemente criticado por Shu Xiang, que acreditava que, se o povo tomasse conhecimento da lei, não demonstraria mais respeito aos seus dirigentes. Contudo, embora esse tipo de tradição de publicidade da lei não tenha desaparecido totalmente nos dois mil anos seguintes, a legislação e a prática do Governo Aberto à Informação (GAl) nada, ou muito pouco, tem a ver com esse legado da tradição legal. De fato, tal herança foi norteada pela reforma econômica e pelas políticas de abertura iniciadas em $1978 .^{2}$

Desde os anos 1980, a China tem gradualmente abandonado o modelo de economia planificada e abraçado políticas de livre mercado. Nesse contexto, dois incentivos foram criados pelo governo chinês para construir governos transparentes. O primeiro tem propósitos econômicos. Com a migração cada vez maior de corporações transnacionais para a China e o intenso desenvolvimento de cidades empresas, um grande número de demandas foi gerado, pressionando os governos em todos os níveis para uma postura mais aberta e transparente ao mundo, bem como em seu mercado doméstico. Essa força motriz ganhou impulso após a exitosa adesão da China à Organização Mundial do Comércio (OMC), em 2001, uma vez que uma das obrigações das leis internacionais para os membros da OMC é a de ampliar a transparência do governo. ${ }^{3} \mathrm{O}$ segundo incentivo é a necessidade de lutar contra a corrupção. O rápido crescimento econômico e a corrupção desenfreada sempre andam juntos, especialmente em um país sem instituições legais muito eficazes como a China. Assim como a luz do sol é o melhor antisséptico, é de grande necessidade para os governos, em todos os níveis, na China, estabelecer o sistema de GAl, que já tem se tornado o símbolo de uma sociedade moderna.

QIUMING, Zuo. The Tso Chuan: the Sixth Year of Zhao Gong [《左传·昭公六年》]

WENJING, Liu. Approaching Democracy Through Transparency: A Comparative Law Study on Chinese Open Government Information. American University International Law Review, v. 26, n. 4, 2011. p. 987.

3 CLARKE, Donald C. China's Legal System and the WTO: Prospects for Compliance, 2. Washington University Global Studies Law Review, 2003. p. 97-98. 
Semelhante à reforma econômica iniciada com o sistema de responsabilidade contratual doméstica na zona rural chinesa, a legislação do GAl também foi adotada com uma abordagem ascendente que foi relativamente cautelosa e pragmática naquela oportunidade. A linhagem do funcionamento do GAI na China pode ser traçada desde as "questões abertas nas vilas" (cunwu gongkal), em nível local, no início dos anos 80. ${ }^{4} \mathrm{Em}$ 1987, o Partido Comunista Chinês (PCC) lançou uma campanha nacional denominada "Duas publicidades e um monitoramento" (liang gongkai, yi jiandu). ${ }^{5}$ Essa campanha inclui disposições para dar publicidade a regras administrativas, procedimentos e resultados, a fim de que o monitoramento público seja aceito em todos os níveis de governo. Desde então, práticas do GAl têm gradualmente se espalhado pelas aldeias, municípios e cidades. ${ }^{6}$ Em janeiro de 2003, as Regras para o Governo Aberto à Informação da Municipalidade de Guangzhou produziram efeito. Em 2004, seguindo a dianteira de Guangzhou, os governos de Shanghai, Beijing, Shenzhen, Hangzhou, Chongqing, Chengdu e Wuhan promulgaram suas próprias regras sobre o GAI. Baseada nos experimentos em um nível governamental mais baixo, uma legislação nacional foi colocada na agenda do Conselho de Estado em 2003. Em 17 de janeiro de 2007, o Conselho de Estado da China aprovou as Regulações da República Popular da China sobre o Governo Aberto à Informação (Regulações GAI), vigentes em 1ㅇ de maio de 2008.

As Regulações GAl estabelecem um procedimento uniforme para a administração do GAI por localidades e agências administrativas, a fim de construir governos mais transparentes, tornar a informação governamental útil ao desenvolvimento econômico e proteger o direito do povo à informação. Ainda que longe da perfeição, tais Regulações, todavia, se firmam como marco notável para as próximas etapas do processo do GAI na China. Existe um exemplo visível a demonstrar esse ponto. Em 12 de maio de 2008, poucos dias após a aplicação das Regulações GAl, o condado de Wenchuan, na Província de Sichuan, no oeste da China, sofreu com um mortal terremoto, de magnitude 8.0 , que matou aproximadamente 80.000 pessoas. $^{7}$ Esse desastre repentino causou enorme abalo nas vidas de milhões de pessoas, mas não causou pânico social, pelo importante motivo de ter havido plena publicidade da informação ao público no tempo oportuno. Os governos responderam rápida e efetivamente e os meios de comunicação informaram de modo hábil, completo,

\footnotetext{
LIANGJIN, Zhou Liangin. Background and Implication of the Chinese Access to Government Ordinance. Law and Society, v. 7, p. 710-711, 2007. p. 710.

5 PIOTRWSKI, Suzanne J.; ZHANG, Yahong; YU, Weiwei Lin; YU, Wenxuan. Key Issues for Implementation of Chinese Open Government Information Regulations. Public Administration Review (Edição especial), p. 129-135, dez. 2009.

6 ZHIFU, Chen. Several Issues with the Chinese Access to Government Information Regulations. Journal of Chinese Public Administration, n. 11, p. 21-23, 2007. p. 21.

7 YONG, Chen; BOOTH, David C. The Wenchuan Earthquake of 2008: Anatomy of a Disaster. Science Press of Beijing and Springer. p. 196-199.
} 
transparente e compreensível, em completo contraste com o terremoto em Tangshan em 1976, quando aconteceu um verdadeiro blackout de notícias. Ainda mais importante, o governo central divulgou o número de mortes causadas pelo terremoto pela primeira vez, o que, até então, era considerado segredo de Estado.

Nas seções seguintes, iremos introduzir os princípios e principais conteúdos incluídos nas Regulações do GAI, bem como as principais deficiências que merecem ser aperfeiçoadas em um futuro próximo. Nosso interesse concentra-se não só nas legislações que o governo chinês criou nessa área, mas também em verificar se são plenamente colocadas em prática, questão a partir da qual apontamos a grande distância/lacuna entre os textos/documentos e a realidade. A última parte aborda o futuro da legislação do GAI na China. Na última parte, vislumbra-se o futuro da legislação GAI na China.

\section{Princípios gerais}

\subsection{Princípios nas Regulações do GAI}

Existem debates calorosos sobre quais princípios deveriam ser incluídos nas legislações sobre o GAl na China, antes da adoção das Regulações GAl e mesmo depois delas. Alguns estudiosos acreditam que somente um princípio fundamental seja suficiente. Esse seria o princípio da publicidade e a exceção da confidencialidade. Outros estudiosos elaboraram suas próprias propostas legislativas para o GAI, pontuando os seis princípios seguintes: direitos civis, transparência, ponderação de interesses, gratuidade, universalidade e garantias. ${ }^{8}$ Entretanto, literalmente, existem, ao todo, outros seis princípios previstos no primeiro capítulo das Regulações GAI, abrangendo três aspectos os quais o governo central considera os mais importantes.

Primeiro, sob a perspectiva dos direitos civis, o GAI deve aderir a três princípios: justiça, equidade e comodidade para o povo (artigo 5). Isso significa que as ações do GAl devem garantir a igualdade a todo o povo chinês. Por um lado, qualquer cidadão, pessoas jurídicas e outras organizações podem igualmente obter informação governamental da qual se tem publicidade por iniciativa do próprio governo, sem qualquer custo adicional. Por outro lado, todos eles podem preencher requerimentos baseados em necessidades especiais sobre tais matérias, conforme sua própria produção, sustento e pesquisa científica e tecnológica. Do mesmo modo, é estritamente proibido não dar tratamento igualitário aos cidadãos, conforme seu grupo étnico, raça, sexo, ocupação, status patrimonial ou crença religiosa, no que se refere à pessoa juridical ou outras organizações, em termos da natureza de seu negócio (empresas estatais,

\footnotetext{
8 HANHUA, Zhou. Some Considerations on Drawing a Proposal of OGI regulations. Law Studies, v. 06, p. 89-91, 2002. p. 89.
} 
privadas ou de capital estrangeiro). Além disso, ao executar suas funções com base no GAl, os governos também devem providenciar fácil acesso, websites e informativos do governo que são mais convenientes ao público a ser informado.

A segunda perspectiva são os princípios da celeridade e exatidão, que dizem respeito à qualidade da informação governamental. De acordo com o artigo 6, a informação governamental deverá ser prontamente e precisamente publicada, o que significa dizer que qualquer atraso na publicidade, caracterizando informação falsa ou incompleta, não será permitido. Esses dois princípios objetivam salvaguardar a credibilidade governamental, reforçando o papel do GAI de servir ao desenvolvimento social e econômico.

0 terceiro contexto se foca em salvaguardar o interesse público. Isso requer que a informação governamental publicada não coloque em risco a segurança estatal, a segurança pública, a segurança econômica e a estabilidade social (artigo 8). Agências administrativas não darão publicidade à informação governamental que envolva segredo de Estado, segredos comerciais ou a privacidade individual (artigo 14, parágrafo quarto). Obviamente, esse princípio - salvaguardar o interesse público - impõe certas limitações ao campo de aplicação do GAI, de modo a proteger o interesse público que porventura os legisladores entendam estar em risco.

A fim de que isso seja garantido, como base das leis administrativas, a legislação do GAl deve seguir o princípio fundamental da legalidade e da razoabilidade no âmbito do direito administrativo chinês, em especial a transparência administrativa e o due process of law. ${ }^{9}$ Entretanto, esses princípios fundamentais das leis administrativas chinesas não são específicos para o GAl, mas constituem os requisitos para qualquer ato administrativo.

\subsection{Publicidade é princípio e confidencialidade é exceção}

A principal controvérsia entre os princípios do GAl é a de onde o princípio da “publicidade é princípio e confidencialidade é exceção" devem ser incluídos. Como o próprio nome indica, esse princípio exige que o governo, em todos os níveis, deve dar a maior publicidade possível às informações governamentais, mantendo o sigilo somente sob situações específicas, explicitamente listadas na lei. Muitos estudiosos apontam que esse deve ser o mais essencial e importante princípio para a legislação chinesa do GAl. Eles acreditam que, sem o direcionamento desse núcleo principal, o governo pode se recusar a divulgar qualquer informação governamental conforme seu livre arbítrio, utilizando-se de termos vagos nas Regulações GAl. Considerando esses fatos, como a primeira legislação oficial sobre GAI na China, as Regras sobre o

9 MING'AN, Jiang. Administrative Law and Administrative Litigation Law. 5. ed. Beijing: Peking University Press, 2011. p. 77. 
Governo Aberto à Informação da Municipalidade de Guangzhou formal e explicitamente estabeleceram o princípio segundo o qual "quase toda informação governamental deve ser publicada e a confidencialidade deve ser a exceção". ${ }^{10}$ Entretanto, "publicidade é princípio e confidencialidade é exceção" não está expressamente regulado pelas Regulações GAl. Isso se deve principalmente ao status legal das Regulações. $\mathrm{Na}$ verdade, as Regulações GAl são somente regulações adotadas pelo Conselho de Estado, que é a última instância administrativa, e não as leis aprovadas pelo Congresso Nacional do Povo (CNP), como órgão de poder supremo do Estado. Isso significa que elas não devem contradizer diretamente a lei da República Popular da China da Tutela dos Segredos de Estado e outras leis correlatas.

\section{Principais conteúdos}

\subsection{Os órgãos do GAl e a definição de "informação governamental”}

Como o termo sugere, os órgãos do GAl são aqueles responsáveis pelo trabalho do GAl. Primeiramente, as agências administrativas são os órgãos mais importantes do GAI, referindo-se especialmente àqueles com status de pessoa jurídica independente, realizando suas funções em seu próprio nome e assumindo obrigações independentemente. Elas devem ter responsabilidades quanto à publicidade da informação governamental arquivada dentro de seu próprio escopo de deveres e funções. Ao contrário, aqueles como organismos internos, instituições temporariamente coordenadas, grupos de trabalho não podem ser reconhecidos como órgãos qualificados do GAI, não possuindo obrigações de publicidade, mesmo se, de fato, obtiverem algum tipo de informação governamental. Em segundo lugar, embora as organizações como o Departamento Meteorológico e a Comissão Regulatória de Títulos não sejam agências administrativas, elas são consideradas órgãos do GAI porque tais organizações têm autorização legal ou regulamentar para exercer as funções de gestão de assuntos públicos. Em terceiro, empresas públicas e instituições que são intimamente relacionadas ao interesse público como educação, saúde, suprimento de água, proteção ambiental devem também dar publicidade à informação produzida ou obtida no curso do fornecimento de serviços públicos. Todavia, uma vez que as Regulações GAl foram aprovadas pelo Conselho de Estado, que é a mais alta instância do corpo executivo da China, estas/tais leis não possuem efeito vinculante sobre a esfera legislativa (congressos em todos os níveis), sobre o Judiciário (cortes e procuradorias em todos os níveis), bem como sobre organizações partidárias que, modernamente, não possuiriam a obrigação de tornar seus documentos públicos.

10 HORSLEY, Jamie P. Introduction on Open Government Information Implementation. Government Information Quarterly, v. 23, n. 1, p. 5-10, 2006. p. 5. 
Seria preferivel incorporar as esferas legislativa e judicial como órgãos do GAI tão logo a lei chinesa do GAl seja decretada em um futuro próximo.

Além disso, as Regulações GAl prescrevem os escritórios especiais para a realização do trabalho do GAl. O Escritório Geral do Conselho de Estado deve ser o departamento nacional encarregado dos trabalhos do GAl, e os escritórios gerais dos governos locais, no nível de condados e acima, devem ser responsáveis por promover, guiar, coordenar e supervisionar o trabalho do GAI dentro de suas áreas administrativas respectivas. Esses escritórios devem assumir matérias específicas do GAl, mantendo e atualizando a informação governamental, organizando uma compilação de guias e relatórios anuais do GAl e conduzindo o exame do sigilo para a agência administrativa à qual o escritório especial pertença (artigo 4). A definição de escritórios especiais para o GAI, de fato, torna a publicidade da informação governamental mais conveniente e mais suave, bem como mais padronizada e, portanto, mais fácil de supervisionar.

“Informação governamental” nas Regulações GAl se refere à informação feita ou obtida pelas agências administrativas ao longo do exercício de suas responsabilidades e gravadas e arquivadas em respeito a determinada forma (artigo 2). De acordo com tal definição, a informação governamental pode ser caracterizada pelos seguintes aspectos. Primeiramente, a informação governamental é formada pelos governos no curso do exercício de suas responsabilidades. Consequentemente, a informação não relacionada ao exercício de suas responsabilidades não pode ser considerada como informação do governo. Esse ponto indica, sobretudo, a informação que diz respeito à matéria interna da agência administrativa, tal como pessoal interno e informação financeira. Em segundo lugar, a informação governamental é feita ou obtida pelo governo, incluindo material de primeira mão feito por eles mesmos e fontes de segunda mão obtidas por terceiros. Apesar disso, seja informação de primeira seja de segunda mão, de acordo com o princípio básico do "quem possui, quem divulga", o governo que possui a informação deve publicá-la, de modo a evitar o atraso, declinando da publicidade ou mesmo fugindo de suas obrigações legais.

Em terceiro lugar, a informação governamental deve ser expressa através de uma forma determinada, tangível. Pode ser tanto por meio de documentos em papel, bem como em formatos eletrônicos e digitais, mas não poderão ser aqueles sem uma forma definida como mensagens orais ou mesmo rumores. Também deve ser pontuado que os governos simplesmente fornecem a informação disponível sem a obrigação de a classificar, categorizar, enumerar ou comparar. Daí que uma questão ocorre: os documentos que pertencem ao processo de investigação pertencem à informação governamental? Embora tais documentos estejam sendo preparados para que produzam as conclusões finais, seria mais significativa sua divulgação ao público, se necessário, uma vez que, em muitas instâncias, revelar todo o processo de formação da decisão vale mais do que simplesmente mostrar as descobertas. 


\subsection{O alcance da publicidade e suas limitações}

Baseado em sua importância e sua relação com o interesse público, a informação governamental é dividida em duas categorias pelas Regulações GAI, sendo algumas informações divulgadas de modo pró-ativo e outras por meio de requerimento. 0 artigo 9 explicitamente regula que a informação deverá ser divulgada pela própria iniciativa do governo, se satisfizer os seguintes critérios básicos: 1) informação que envolva interesses vitais dos cidadãos, pessoas jurídicas e outras organizações; 2) informação sobre a qual se deve dar o mais amplo conhecimento ou sobre a qual o público em geral deva tomar parte; 3) informação que demonstre estrutura, função e procedimento de trabalho de um ou outro tema relacionado ao governo; e 4) outra informação que deva ser divulgada pela própria iniciativa do governo de acordo com leis, regulações e relevantes provisões estatais. Além das provisões gerais, tendo em vista suas várias competências, foram atribuídas aos governos, em seus diferentes níveis, as mais diversas responsabilidades nos artigos 10-12, respectivamente. Como medida contra eventos públicos repentinos, por exemplo, os governos no nível de condados e acima deles e seus departamentos focam preferencialmente em planos de emergência para informações de alerta precoce e medidas de combate, enquanto o governo no nível de cidades, dividido entre distritos e condados, deve divulgar informação sobre a gestão, uso e distribuição das doações sociais de fundos em caso de emergências e assistência a desastres etc., e os governos de nível municipal devem se responsabilizar pela publicidade da informação sobre a distribuição de doações sociais em fundos em caso de emergência e assistência a desastres etc.

Como as informações podem ser disponibilizadas através de requerimento, o artigo 13 das Regulações GAI prescreve amplamente que, junto à informação governamental disponibilizada por iniciativa do governo, cidadãos, pessoas jurídicas e outras organizações poderão também, baseados em necessidades especiais que digam respeito a sua própria produção, subsistência e pesquisa científica e tecnológica (as denominadas "três necessidades especiais"), preencher requerimentos ao governo, em todos os níveis, a fim de obter relevante informação governamental. Isso significaria dizer que as solicitações podem ser rejeitadas pelas agências administrativas se a informação governamental requerida pelos solicitantes for considerada desvinculada das três necessidades especiais acima mencionadas? Certamente, o governo tende a adotar uma explicação bastante restrita a esse respeito. De fato, muitos governos em todos os níveis na China frequentemente se recusam a dar publicidade à informação governamental invocando tal argumento.

Todavia, eles interpretam, de modo errôneo e proposital, as implicações legais dessa regulação. As três necessidades especiais são simplesmente enumeradas de modo exemplificativo no artigo, sendo impossivel esgotar todas as necessidades 
especiais em que os requerentes se baseiam. Além dessas três necessidades, os solicitantes podem e devem possuir outros vários argumentos a fim de requerer a divulgação da publicidade governamental. Uma vez que o conceito de "necessidades especiais" é muito ambíguo para ser definido de modo claro, as cortes, em todos os níveis, devem dar a interpretação mais ampla possível, de modo a se limitar o critério adotado pelas agências administrativas, incentivando os governos a agirem em concordância com a lei e construindo um governo transparente na China.

Por outro lado, as Regulações GAI impõem, do mesmo modo, várias limitações no âmbito do GAI. Existe um princípio geral no artigo 8, proibindo a divulgação de informação governamental que venha a colocar em risco a segurança estatal, a segurança pública e econômica e a estabilidade social. Além disso, o artigo 14 ressalta que as agências administrativas não podem divulgar informação do governo que envolva segredos de Estado, segredos comerciais e privacidade do indivíduo. É óbvio que o artigo 8 é muito mais restrito do que o artigo 14, deixando grande margem para o arbítrio governamental determinar o que se entende por "segurança estatal, segurança pública, segurança econômica e estabilidade social", especialmente no momento em que manter a estabilidade social era algo constantemente priorizado nas agendas.

Deixando tal questão de lado, o artigo 14 possui suas próprias implicações. Primeiramente, seus mecanismos devem ser estabelecidos e aperfeiçoados pelas agências administrativas que examinam a informação governamental a ser divulgada de acordo com as provisões da Lei de Tutela dos Segredos de Estado e outras leis, regulações e provisões estatais relevantes. Em segundo lugar, a informação que diz respeito aos segredos de Estado, segredos comerciais e privacidade é tratada de modo diferente. Por um lado, a informação é absolutamente proibida de ser liberada ao público, quando analisada como sendo segredo estatal. De acordo com o artigo 9 da Lei de Tutela dos Segredos de Estado alterada em 2010, o segredo estatal inclui 7 itens de grande amplitude: 1) decisões políticas sobre assuntos de Estado; 2) questões afetas à defesa nacional e às atividades das forças armadas; 3) atividades diplomáticas e assuntos relacionados a questões estrangeiras; 4) sigilo nas áreas da economia nacional e desenvolvimento social; 5) segredos relacionados à ciência e tecnologia; 6) segredos afetos a atividades de tutela da segurança estatal e a investigação de ofensas criminais; 7) quaisquer outros segredos determinados pela Administração do Estado para a Proteção dos Segredos Estatais. Por outro lado, no que diz respeito ao segredo de informações comerciais e privacidade individual, estes poderão ser publicados com o consentimento dos titulares dos direitos ou se o governo acreditar que a confidencialidade possa causar um impacto maior no interesse público. Nesse caso, os governos devem cuidadosamente sopesar os interesses privados com os interesses públicos, de acordo com o princípio da ponderação de interesses. Se a publicação infringir direitos e interesses legítimos, os titulares de 
direitos e terceiros potencialmente atingidos poderão demandar as cortes a fim de verem declarados ilegais tais atos administrativos, buscando, consequentemente, a correspondente compensação.

\subsection{Métodos e procedimentos para a publicidade}

Existem diferentes exigências para procedimentos abertos entre a informação por iniciativa própria do governo e por solicitação. Para a informação governamental a ser publicada pela iniciativa das agências administrativas, as Regulações GAI exigem que tais órgãos sigam o princípio da conveniência para o povo. Primeiramente, o governo deve compilar e publicar guias e catálogos do GAl e atualizá-los em tempo hábil (artigo 9,1). Entre eles, os guias GAl devem incluir tanto os conteúdos como os tipos de informação governamental, o sistema de catalogação, os métodos para se obter informação, o nome, endereço do escritório, horário de funcionamento, número de telefone de contato, número do fax e endereço de email do escritório para o trabaIho do GAI (artigo 19, 2). Os catálogos do GAl devem incluir conteúdos como o índice, o nome da informação, o sumário do conteúdo das informações e a data de criação da informação (artigo 19, 3).

Em segundo lugar, de modo a dar acesso à informação, a informação governamental deverá ser disponibilizada das mais diversas formas, por meio de informativos, websites oficiais, coletivas de imprensa, bem como por meio de jornais e outras publicações, como rádio, televisão e outros métodos que a tornem facilmente acessível ao público (artigo 15). Ainda, os governos, em todos os níveis, devem estruturar a informação governamental em pontos de leitura nos arquivos estatais e bibliotecas públicas e providenciar instalações e equipamentos apropriados, a fim de tornar o mais conveniente possível aos cidadãos, pessoas jurídicas e outras organizações o acesso à informação governamental (artigo 16, 1). Além disso, os governos devem estabelecer, conforme necessário, locais e estabelecimentos, tais como salas de leitura, estações de requerimento de materiais, quadros de avisos e telas eletrônicas de informação, a fim de publicar a informação governamental (artigo 16, 2).

Em terceiro lugar, em respeito às autoridades, de um modo geral, agências administrativas devem ser responsabilizadas pela divulgação de informações governamentais por elas produzidas e, aquelas agências que armazenam a informação obtida através do povo, possuem a responsabilidade de publicá-las (artigo 17). De modo a garantir sua efetividade e qualidade, a informação governamental a ser divulgada proativamente deve ser publicada dentro de 20 dias úteis, contados da data a partir da qual a informação for formada ou modificada (artigo 18). Naturalmente, esse período pode ser modificado se outras leis ou regulações tiveram disposições diferentes nesse sentido. 
Para a informação solicitada por qualquer do povo, as Regulações GAI também estabelecem os requerimentos para os requerentes assim como para os governos. Até onde diga respeito aos requerentes, os mesmos deverão preencher as solicitações através de um formulário escrito, incluindo-se um formulário digital e eletrônico, com exceção feita ao formulário verbal para aqueles que realmente tenham dificuldades para preenchê-los (artigo 20,1). Os requerimentos devem incluir os seguintes conteúdos: 1) o nome do indivíduo ou organização solicitante, o pedido e os meios de contato; 2) uma descrição da informação governamental a que se quer dar publicidade; e 3) requisitos conforme o formato no qual a informação governamental solicitada deverá ser fornecida (artigo 20, 2). Se houver evidência de que a informação relacionada, fornecida pelas agências administrativas, é imprecisa, os requerentes também têm o direito de demandar correções (artigo 25, 2).

Por parte dos governos, os mesmos deverão seguir rigorosamente os procedimentos prescritos pelas Regulações GAl. Após receberem as solicitações, os governos deverão responder prontamente na maior amplitude possível (artigo 24, 1). Se assim não puder ser feito, agências administrativas deverão apresentar uma resposta em 15 dias úteis do recebimento do requerimento, prorrogável por não mais que 30 dias úteis (artigo 24, 2). Não obstante, as agências administrativas deverão examinar a informação no que se inclui uma análise sobre seu conteúdo, de modo a averiguar segredos de Estado, segredos comerciais ou privacidade individual, antes de responder aos requerentes. Se o governo requerido controlar algum conteúdo que não puder ser publicado, mas que possa ser tratado mediante diferenciação, os governos deverão fornecer o conteúdo da informação que deve ser publicada (artigo 22). Se a informação envolver segredo comercial ou a privacidade individual e a publicidade puder infringir interesse legítimo de terceiro, a agência administrativa deverá peticionar ao terceiro interessado de modo a provocar sua manifestação (artigo 23). Se o terceiro não concordar com a divulgação da informação, a mesma não poderá ser divulgada. Todavia, se a agência administrativa considerar que a confidencialidade possa vir a influenciar o interesse público, deverá publicar a informação e notificar o terceiro interessado sobre o conteúdo que se decidiu divulgar e as razões para tal (artigo 23).

O ultimo tópico é sobre taxas. 0 artigo 27 enfatiza que as agências administrativas não podem recolher quaisquer taxas, salvo aquelas taxas baseadas no custo, relativas aos gastos com a busca, fotocópias, postagem e similares. Além disso, uma taxa considerável pode ser reduzida ou abonada para o cidadão com dificuldades econômicas reais, devendo ser providenciada, ainda, a competente assistência para os cidadãos que tiverem dificuldades de leitura ou obstáculos visuais ou auditivos (artigo 28). Entretanto, deve-se ressaltar que as pessoas jurídicas e outras organizações não recebem tal tratamento. 


\subsection{Supervisão e garantias}

As Regulações GAl adotaram várias medidas para garantir o acesso à informação ao povo. Primeiramente, os governos, em todos os seus níveis, devem publicar seus relatórios anuais sobre o trabalho da abertura da informação governamental antes de 31 de março de cada ano (artigo 31). 0 relatório anual deve incluir os seguintes conteúdos: 1) informação sobre a publicidade da informação governamental de iniciativa própria das agências administrativas; 2) informação revelando a informação governamental pública a pedido e os requerimentos que foram negados; 3) informação sobre o recolhimento de taxas, suas reduções e isenções que dizem respeito ao GAl; 4) informação sobre solicitações para pedido de reconsideração e arquivamento de ações administrativas que dizem respeito ao GAl; 5) os maiores problemas quanto ao trabalho do GAl e a informação sobre seus avanços/seu aprimoramento; e 6) outros itens que necessitem ser relatados (artigo 32).

Em segundo lugar, o departamento encarregado pelo trabalho do GAl e pela supervisão das agências deverá ser o responsável por supervisionar e inspecionar a implementação do GAI (artigo 30). Se uma agência administrativa violar as disposições das Regulações GAl e se incorrer em qualquer um dos comportamentos listados pelo artigo 35, a agência fiscalizadora ou a agência administrativa superior deverá determinar que a agência administrativa corrija a situação. Se as circunstâncias forem sérias, penalidades administrativas serão impostas, de acordo com a lei, sobre a pessoa diretamente no comando da agência administrativa, bem como sobre outras pessoas diretamente responsáveis (artigo 35). Se qualquer uma das seguintes condutas constituir crime, a responsabilidade criminal deverá ser perquirida em conformidade com a lei: 1) falha ao preencher, em concordância com a lei, as obrigações do GAl; 2) falha ao atualizar em tempo hábil os conteúdos da informação governamental que tiver de ser publicada em guias do GAl e catálogos do GAl; 3) recolher taxas violando as disposições sobre o tema; 4) fornecer informação governamental como serviço remunerado através de outras organizações e indivíduos; 5) publicar informação governamental que não deveria ser publicada; e 6) outras ações que violem as disposições dessas Regulações.

Como se diz em "sem garantias, sem direito", ações judiciais são a última, mas a mais importante medida para salvaguardar a implementação das Regulações GAl. Se os cidadãos, pessoas jurídicas ou outras organizações creem que determinado ato administrativo de uma agência administrativa no exercício do GAl tenha infringido direitos e interesses legítimos, eles podem, de acordo com a lei, solicitar pedido de reconsideração ou registrar uma ação administrativa (artigo 33, 2). Essa é uma disposição das Regulações GAl que diz respeito a ações judiciais do GAl, sendo necessário, posteriormente, encontrar instruções detalhadas. Não surpreende que, em 29 de julho de 2011, a Suprema Corte Chinesa tenha divulgado uma 
interpretação judicial sobre o contencioso no GAl. Essa interpretação judicial fornece um direcionamento legal bastante claro ao se admitir uma ação judicial do GAl sobre qual agência será a ré, o ônus da prova e que tipo de julgamento deve ser feito sob as mais diferentes circunstâncias.

Além disso, como uma espécie de contencioso administrativo, as ações judiciais do GAl podem também seguir as disposições previstas na Lei do Contencioso Administrativo da República Popular da China (LCARPC), promulgada em 1989 e alterada, pela primeira vez, há mais de vinte anos. De acordo com a nova versão da LCARPC, que entrou em vigor em primeiro de maio de 2015 , casos do GAl podem ser julgados pelo processo sumário em vez de pelo processo convencional anterior, 0 que aceleraria o percurso do processo e aprimoraria a eficiência das ações judiciais do GAl.

\section{Várias deficiências}

\subsection{Falta de bases constitucionais claras}

Nos anos de 1999 e 2004, as emendas "A construção do país sob o Estado de Direito" e "O Estado respeita e preserva os direitos humanos" foram respectivamente escritas na Constituição de 1982. Isso representou um grande passo para o desenvolvimento constitucional da China. Nesse contexto, a China acelerou o passo no sentido de construir um governo transparente, adotando as Regulações GAl em 2007. Todavia, a liberdade de informação ou o direito à verdade ainda continuam sendo direitos humanos fundamentais não reconhecidos e preservados na Constituição vigente. Em outras palavras, não existe uma base constitucional clara para a legislação e a prática do GAI na China. Embora, na teoria, possa derivar da liberdade de expressão presente no artigo 35 da Constituição de 1982, na prática, tal interpretação constitucional, até então, ainda não foi feita, uma vez que o Comitê Permanente do Congresso Nacional do Povo (CPCNP), a única instituição responsável por interpretações constitucionais, é desleixado no cumprimento dessa função. Por essa razão, os propósitos das Regulações GAl são mais supervisionar os governos e manter o crescimento econômico do que defender a liberdade de informação ou o direito à verdade como o mais importante direito humano. Isso, de fato, faz uma grande diferença.

\subsection{Limitações legais}

Como as Regulações GAI são somente tipos de regulações sujeitas à lei, estas enfrentam obstáculos e desafios resultantes das disposições de várias leis que eventualmente enfraquecem a efetividade do GAI na prática. Primeiramente quando em 
conflito com a LTSE, as provisões das Regulações do GAl devem ceder caminho àquela lei. Em contraste com a legislação do GAI, o principal princípio da LTSE é "o sigilo é princípio enquanto a confidencialidade é exceção". Além disso, a definição de segredo de Estado para a LTSE é tão ampla e incerta que mesmo questões como "segredos nas áreas da economia nacional e desenvolvimento social" podem ser consideradas segredo, deixando muito espaço para o arbítrio dos departamentos de proteção do segredo do Estado. ${ }^{11}$ Como resultado, é relativamente fácil para alguns governos rejeitar a liberação de informação governamental com a justificativa de que concerne a fins secretos do Estado. Ainda pior é o fato de que tais decisões não podem ser desafiadas e revisadas por meio de processos judiciais.

Em segundo lugar, a finalidade do GAI pode ser substancialmente limitada pela Lei dos Arquivos da República Federativa da China. Essa lei enfatiza a gestão e a proteção dos acervos, impondo muitas restrições à publicação e uso dos arquivos. A maioria das informações governamentais históricas, tais como as de reorganização das empresas estatais, reassentamento de veteranos e documentos relativos ao período da Revolução Cultural, foi armazenada em arquivos e não foi aberta ao público até três décadas atrás. Por isso, o modo de publicar a informação governamental histórica é outro assunto difícil de ser resolvido no futuro.

Em terceiro lugar, os requerimentos nas Regulações GAI podem violar as disposições sobre a Lei dos Funcionários Públicos da República Popular da China. De acordo com seu artigo 12, funcionários públicos devem manter a confidencialidade para com o Estado e os segredos relacionados ao ambiente de trabalho. Entretanto, não existe nenhuma interpretação legal detalhada sobre o conceito de "segredos no ambiente de trabalho", o que quase significa estabelecer outro novo tipo de exceção dos segredos de Estado, prevalecendo sobre as disposições das Regulações do GAI em sua aplicação. Por essa razão, é necessário esclarecer o conteúdo de "segredos no ambiente de trabalho" que não pode ficar acima do campo de aplicação dos "segredos comerciais" e a "privacidade" regida pelas Regulações GAl.

\subsection{Restrições da Lei do Contencioso Administrativo}

Existem também muitas anomalias no que diz respeito à tutela judicial. De acordo com as Regulações do GAl, cidadãos, pessoas jurídicas e outras organizações, ao acreditarem que um ato administrativo específico de uma agência administrativa em sua missão no GAI tenha infringido seus direitos e interesses legítimos, podem, em conformidade com a lei, sujeitar-se a um contencioso administrativo.

\footnotetext{
${ }^{11}$ FUJUN, Shen. Establishing the System of Safeguarding Secrecy in Accordance with OGI System: From the Perspective of Amending LSSS. Law Journal, v. 9, p. 50, 2009. p. 50.
} 
Primeiramente, os requerentes devem ter o ônus da prova no caso das ações administrativas que infrinjam seus próprios direitos e interesses legítimos. Assim, é fundamental definir quais direitos e interesses legítimos se incluem nisso. Infelizmente, as disposições que dizem respeito ao âmbito dos casos admitidos pela LCA adotaram uma abordagem restritiva, limitada somente aos direitos de propriedade e personalidade. Nesse caso, outros tipos de direitos, tais como a liberdade de expressão ou a liberdade de informação, não podem ser reconhecidos nas bases da reclamação. Em segundo lugar, embora a LCARPC alterada não diferencie mais ações administrativas específicas de ações administrativas abstratas, não significa que o Judiciário não possa revisar/controlar diretamente a legalidade das ações abstratas. A revisão judicial não se restringe apenas a regulações, mas deve, ainda, ter caráter suplementar, sem se desvincular de casos específicos. Além disso, o sistema de compensação do Estado na China está longe da perfeição e somente compensa perdas diretas referentes a direitos e interesses legítimos do requerente, mas não os danos indiretos que as ações administrativas ilegais sobre o GAl tendem a causar.

Finalmente, embora a interpretação judicial sobre o contencioso no GAl tenha sido promulgada pela Suprema Corte da China, ela trata muito pouco do procedimento de publicação e, portanto, não influencia a ampla discricionariedade de que as agências administrativas gozam, nos procedimentos administrativos pertinentes.

Aliás, mesmo se a interpretação judicial possa compensar algumas deficiências procedimentais que as Regulações GAl possuam e ainda que forneçam provisões mais efetivas para os tribunais que possam ser seguidas por toda nação, a mesma não é compulsória em procedimentos administrativos, uma vez que as agências administrativas não se vinculam às interpretações judiciais da Suprema Corte da China a menos que suas decisões sejam julgadas pelos tribunais.

\section{Alguns aspectos na prática}

Um aspecto na prática diz respeito à tradição de longa data de se manter o sigilo, enraizada na cultura política da China, que continua a exercer substancial influência na esfera política atual. Para os governos e funcionários, o ato de publicar a informação governamental pode ser criticado pelos cidadãos e pela grande massa dos meios de comunicação e, ainda, condenado por seus funcionários de alto escaIão, enquanto o ato de manter o sigilo pode não falhar em nenhuma circunstância. Como órgãos racionais, os governos, em todos os níveis, não possuem incentivo suficiente para divulgar a informação governamental por suas próprias mãos e o mais rápido possível. Por exemplo, poucas agências governamentais, em qualquer nivel, alinharam-se ativamente aos requerimentos do GAI para divulgar informações e dar publicidade aos relatórios anualmente até 31 de março a cada ano. Dados no The Prosecutor Daily mostram que, à meia-noite do dia 31 de março de 2009, 
nove conselhos de Estado, 27 ministros, 13 das 16 organizações diretamente subordinadas, cinco de seis agências administrativas, 11 de 14 instituições diretamente subordinadas e 15 das 19 administrações nacionais ainda não tinham divulgado seu relatório anual do GAl a tempo. ${ }^{12}$ Tais resultados demonstram que as Regulações ainda têm um longo caminho para percorrer até uma implementação nacional consistente.

Outro aspecto foca no papel do Judiciário no GAl. Como último recurso para salvaguardar a implementação das Regulações GAI, a revisão judicial enfrenta muitas barreiras decorrentes de todo o sistema judicial. Os tribunais, em todos os níveis, frequentemente têm de seguir as instruções e as direções dos funcionários das agências administrativas e dos líderes do Comitê para Assuntos Políticos e Legislativos do CNP. Consequentemente, as ações judiciais sobre o GAI são tão suscetíveis a intervenções impróprias por parte dos funcionários administrativos e líderes partidários que os demandantes acreditam que seus direitos e interesses legítimos ofendidos têm poucas chances de êxito em uma ação judicial. Em resumo, a independência judicial não pode ser assegurada e garantida no ambiente político atual da China. Contudo, desde 2012, o novo governo central chinês promoveu uma série de grandes reformas para fortalecer o Estado de Direito, dentre as quais está a reforma do Judiciário. Para proteger a autonomia do Judiciário, os líderes e funcionários que interferem em decisões judiciais individuais devem ter seus nomes registrados e ser responsabilizados por suas ações legais ou ilegais. Essa é uma medida tipicamente chinesa e é muito cedo para afirmar se vai resultar na ampliação do controle judicial para o GAl.

É inspirador observar que, com o extraordinário progresso do rule of law e o rápido desenvolvimento da rede nos últimos anos, os cidadãos da China têm exigido um governo cada vez mais transparente e pressionado os governos a uma maior abertura para o mundo, bem como para o seu povo. Muitas organizações não governamentais (ONGs) da sociedade civil, incluindo-se instituições acadêmicas em algumas universidades, têm realizado grandes esforços para melhorar a conscientização sobre o GAl entre os cidadãos comuns e, de forma ainda mais importante, aperfeiçoado/aprimorado o mecanismo de trabalho do GAI na China. Por exemplo, o Centro de Estudos e Apoio para a Participação Popular (Center For Public Participation Studies and Supports - CPPSS) da Faculdade de Direito da Universidade de Pequim iniciou, depois de 2009, a temática do China Administrative Transparency Annual Watch, promovendo observações completas e avaliações significativas sobre a construção da transparência nos governos da China, o que desempenhou importante papel na promoção e supervisão do trabalho do GAl em todos os níveis de governo

\footnotetext{
12 YAN, Zhi. Open Government Information: How many governmental departments have not handed in their 'paper' yet. The Prosecutor Daily. Disponivel em: <http://unn.people.com.cn/GB/14748/9092952.html>. Acesso em: 05 maio 2015.
} 
chinês. ${ }^{13}$ Pode-se concluir que os milhões de pessoas comuns da China são as molas propulsoras principais para fazer com que o GAl seja melhor que antes.

\section{O futuro do GAI na China}

As Regulações GAl de 2007 são extraordinariamente importantes para o governo chinês e seu povo, por representarem uma quebra qualitativa com o passado, sendo a primeira tentativa, em nível nacional, de criar transparência nos governos. Desde que se tomou um caminho irreversivel com o rule of law e a proteção dos direitos humanos, podemos prever que a China irá editar sua primeira Lei do GAI na próxima década. Entretanto, há de se notar que é somente o primeiro passo na grande marcha para o GAl. É quase impossível para a China realizar completamente a proteção à liberdade de informação e construir um governo transparente da noite para o dia. Além de maiores avanços nas legislações sobre o GAl, a China ainda necessitará de um longo tempo para aperfeiçoar seu sistema legal e garantir a independência do Judiciário, bem como formar uma cultura política de abertura por toda a sociedade.

The First Step in the Long March: the Legislation and Practice of Open Government Information in China (OGI)

Abstract: The main topic of the above-referenced article concerns the legal and practical aspects of the so-called "Open Government Information (OGI)" in China. The text demonstrates the difficulties of implementation and development of a subject at the heart of the Chinese government's concerns: the attempt to abandon its planned economy model, forming new, more transparent governments, so as to realise free-market policies. In this context, the authors address the development of certain basic concepts, such as advertising and information in line with the specificities of Chinese reality. They also focus on the exceptions involved in such rights and their legal limitations, identifying the lack of clear constitutional bases as the main problem. In any case, the article presents a current, up-to-date perspective on the right to information in China, illustrated by practical case studies and projections of the future roads to be travelled by the Open Chinese government.

Key words: Access to information. China. Open Government Information.

\section{Referências}

CENTER FOR PUBLIC PARTICIPATION STUDIES AND SUPPORTS (CPPSS). China Administrative Transparency Annual Watch: 2009. Beijing: Law Press, 2011.

CHINA. Guangzhou Shi Zhengfu Xinxi Gongkai Guiding The Rules on Open Government Information of Guangzhou Municipality. Decreto n. 8 Governo Popular da Província de, 6 nov. 2002, em vigor a partir de 1ํjan. 2003.

13 CENTER FOR PUBLIC PARTICIPATION STUDIES AND SUPPORTS (CPPSS). China Administrative Transparency Annual Watch: 2009. Beijing: Law Press, 2011. 
CHINA. Zhonghua Renmin Gongheguo Baoshou Guojia Mimi Fa. The Law of People's Republic of China on Safeguarding State Secrets, lei/decreto promulgado(a) pelo Comitê Permanente do Congresso Popular Nacional, 05 set. 1988, em vigor a partir de 1ํo out. 2010.

CHINA. Zhonghua Renmin Gongheguo Dang'an Fa. Archives Law of the People's Republic of China, lei adotada pelo Comitê Permanente do Congresso Popular Nacional, 05 set. 1987, em vigor a partir de $1^{\circ}$ jan. 1988, revisado(a) em 05 jul. 1999.

CHINA. Zhonghua Renmin Gongheguo Gongwuyuan Fa. Civil Servant Law of the People's Republic of China, lei adotada pelo Comitê Permanente do Congresso Popular Nacional, 27 abr. 2005, em vigor a partir de 1ํjan. 2006. Disponivel em: <http://www.npc.gov.cn/englishnpc/Law/2007-12/13/ content_1384101.htm>. Acesso em: 03 maio 2015.

CHINA. Zhonghua Renmin Gongheguo Xingzheng Susong Fa. Administrative Litigation Law of the People's Republic of Chinalei adotada pelo Congresso Popular Nacional, 04 abr. 1989. Disponível em: <http://www.china.org.cn/government/laws/2007-04/16/content_1207336.htm>. Acesso em: 03 maio 2015.

CHINA. Zhonghua Renmin Gongheguo Zhengfu Xinxi Gongkai Tiaoli Regulations of the People's Republic of China on Open Government Information, lei adotada pelo Conselho Estadual em 05 abr. 2007, em vigor a partir de $1^{ }$maio 2008.

CHINA. Zuigao Renmin Fayuan Guanyu Shenli Zhengfu Xinxi Gongkai Xingzheng Anjian Ruogan Wenti De Guiding. Decisão da Supreme People's Court (on Several Issues Concerning the Trial of Administrative Cases About Open Government Information), proferida pela Suprema Corte Popular, jul. 2011, em vigor a partir de 12 ago. 2011. Disponivel em: <http://www.lawinfochina.com/Display. aspx?lib=law\&ID=8897>. Acesso em: 05 maio 2015.

CLARKE, Donald C. China's Legal System and the WTO: Prospects for Compliance, 2. Washington University Global Studies Law Review, 2003. p. 97-98.

FUJUN, Shen. Establishing the System of Safeguarding Secrecy in Accordance with OGI System: From the Perspective of Amending LSSS. Law Journal, v. 9, p. 50, 2009.

HANHUA, Zhou. Some Considerations on Drawing a Proposal of OGI regulations. Law Studies, v. 06, p. 89-91, 2002.

HORSLEY, Jamie P. Introduction on Open Government Information Implementation. Government Information Quarterly, v. 23, n. 1, p. 5-10, 2006.

LIANGJIN, Zhou Liangiin. Background and Implication of the Chinese Access to Government Ordinance. Law and Society, v. 7, p. 710-711, 2007.

MING'AN, Jiang. Administrative Law and Administrative Litigation Law. 5. ed. Beijing: Peking University Press, 2011.

MING'AN, Jiang. Course on Administrative Litigation Law. Beijing: China Legal Publishing House, 2011.

PIOTRWSKI, Suzanne J.; ZHANG, Yahong; YU, Weiwei Lin; YU, Wenxuan. Key Issues for Implementation of Chinese Open Government Information Regulations. Public Administration Review (Edição especial), p. 129-135, dez. 2009.

QIUMING, Zuo. The Tso Chuan: The Sixth Year of Zhao Gong.

WENJING, Liu. Approaching Democracy Through Transparency: A Comparative Law Study on Chinese Open Government Information. American University International Law Review, v. 26, n. 4, 2011.

YAN, Zhi. Open Government Information: How many governmental departments have not handed in their 'paper' yet. The Prosecutor Daily. Disponível em: <http://unn.people.com.cn/GB/14748/9092952. html>. Acesso em: 05 maio 2015. 
YONG, Chen; BOOTH, David C. The Wenchuan Earthquake of 2008: Anatomy of a Disaster. Science Press of Beijing and Springer. p.196-199.

ZHIFU, Chen. Several Issues with the Chinese Access to Government Information Regulations . Journal of Chinese Public Administration, n. 11, p. 21-23, 2007.

Informação bibliográfica deste texto, conforme a NBR 6023:2002 da Associação Brasileira de Normas Técnicas (ABNT):

MING'AN, Jiang; DAOMING, Tan. O primeiro passo na Grande Marcha: legislação e prática do Governo Aberto à Informação (GAl) na China. A\&C - Revista de Direito Administrativo \& Constitucional, Belo Horizonte, ano 15, n. 61, p. 51-69, jul./set. 2015.

Recebido em: 06.05.2015

Aprovado em: 18.06.2015 